\title{
GENDER AND ADMINISTRATION
}

\section{Anne Marie Goetz}

There is a feature of institutional failure in development which has not, by and large, been a concern of either the conventional development administration literature, or the efforts over the last decade to improve the accountability of public administration. It is the persistent failure of public service delivery agencies to include women equitably amongst the 'publics' they ostensibly serve. Feminist policy advocates have responded to this problem since the 1970 s with the demand that states and development institutions 'integrate' women to development policy and practice. But despite the fact that the 'integration of women in development' is now a virtually obligatory part of catechisms of social and economic justice in most developing states, the pursuit of gender policy ambitions through public institutions has improved women's condition only at the margins of survival at best, and has consistently failed to advance women's participation in decision-making, whether it be in the family, the community, bureaucratic institutions, or the state. This persistent institutional failure to respond to women's needs and interests in development, despite constant efforts by gender policy advocates to adapt feminist policy ambitions to changing development agendas, and despite the sometimes genuine good intentions of governments, invites theoretical attention to the gender dimensions and politics of public administration which underwrite this particular pattern of institutional failure.

The problem here is not just that feminist policy ambitions are being ground to dust by the slow crunch of bureaucratic gears in the way of so much redistributive policy. Rather, this article will argue that public administration is in itself a gendered and gendering process, such that its outcomes, internal organization, and culture reflect and promote the interests of men. 'Gender' refers to the socially constructed and institutionalized forms of identity which are attached to biological sex differences, and 'gendering' is the process producing these forms, through the granting or withholding of significant social, political, and economic resources and values. The economic and political centrality of public service agencies in development contexts is such that they are in a position to contribute to this latter process through what they provide or regulate. Because of this, they can reflect and reproduce the pathologies of women's marginality which result from the interaction of a range of other institutions. At the same time, they are an important site for making a public stance against this process, and for transforming it in women's interests. For this to be possible, for gender policy in development to be successful, it is important to understand not just the role of public administration in producing gendered outcomes, but the role of gender in structuring power and opportunity within administration, and the links between these two processes.

This article sets out a conceptual framework for the analysis of the gender of public administration in development. The focus will be primarily on public service delivery in the agricultural sector, as this remains the institutional arena most resistant to the admission of women's needs and interests in agrarian economies.

\section{GENDER POLICY GOALS IN DEVELOPMENT: A REVIEW OF IMPLEMENTATION AND INSTITUTIONALIZATION}

The traditional technicist view of bureaucratic organizations holds that administration operates on meritorious principles which are gender- (and classand race-) neutral, and that neither the sex of bureaucrats, nor of policy recipients, makes a difference to the objectives of policy, to the ways policies are implemented, or to the ways in which the interests of men and women are institutionalized in public administration. A brief survey of the topography of public administration in development offers evidence to challenge these assumptions of gender-neutrality.

Analysts of gender policy in development have pointed to a gender-specific pattern in the way public service institutions address people's needs in development. Women are most often the objects of public administration for sex-typed services which target women's reproductive functions - either biological (as
I use the term 'gender policy' as a shorthand for policies designed to redistribute resources and values in development between the sexes so as to transform asymmetries of significance and power associated with gender difference. It is distinct from the more familiar term 'Women in Development' (WID) policy in that the stress on gender is a reminder that men are as much constrained by as implicated in systems of domination, and that attempts to redress gender inequities must directly involve men. WID policy, on the other hand, has preoccupied itself with easing women's access to development, which has tended to detract attention from the relational dimensions of their disprivilege. 
in the case of family planning services), or social (as in community management services). Public administration concerned with 'mainstream' development sectors such as industry, agriculture, and infrastructure, tend to exclude the majority of women outright. This exclusion is most striking in the case of agricultural sector services, despite evidence of women's centrality to subsistence agriculture in many agrarian economies. Across Africa for example, where women are responsible for 60 per cent of total agricultural output and 80 per cent of food production (Downs 1991), women farmers receive less than two per cent of extension contacts (Lele 1991:58; Staudt 1978a,b; 1985). Kathleen Staudt has observed that the bias against women farm managers increases in intensity as the value of the agricultural service increases (Staudt $1978 \mathrm{~b}$ ), and this is true for a range of other agricultural institutions such as marketing boards, research institutions, and credit agencies (Downs 1991). That these services overlook women farmers raises serious doubts about the merit-based principles which supposedly guide bureaucratic processes of need identification and satisfaction.

Staudt's important early study of agricultural extension in Kenya pointed to the absence of clear gender policy goals as the cause of administrative neglect (1978b:401). But although it has since become customary to espouse such goals, outcomes remain broadly similar. For example, despite policy rhetoric claiming gender-egalitarian approaches in both state and non-governmental rural credit and incomegenerating programmes in Bangladesh, studies have shown common and consistent gender-differentials in project implementation. Fewer women than men are members of these programmes, but even where they form a majority, as in the Grameen Bank or the Bangladesh Rural Action Committee, the credit they receive is not proportional to their representation as members. Individually, they receive credit in much smaller amounts than men, training is for low-profit, sex-stereotyped activities, and unlike men, their programme membership may be made conditional on their acceptance of family planning measures (Feldman and McCarthy 1984; Saffilios-Rothschild and Mahmoud 1989; Goetz 1991).

The political history of feminist perspectives on development and efforts to institutionalize women's interests has followed a similar trajectory of marginalization. Bureaux concerned with gender and development in states and development administrations, and their research and policy initiatives, are often perched on the peripheries of 'mainstream' development concerns; never in the economic planning divisions, often in the social welfare sectors. That the World Bank's

\footnotetext{
2 In this the Gender and Development (GAD) literature follows a pattern in the rich and also vast popular and academic feminist literature on women and work which follows 'human capital"
} assumptions. Thus women's negative organizational prospects tend
Division of Women in Development is located in its Population and Human Resources Department, for example, clearly signals the Bank's view of women's place. Units such as these command few resources in staff or funds. The development agencies of the UN the system which sponsored the international Decade for Women (1976-1985) - allocate just 0.2 per cent of their overall budget to projects which benefit women; less than 1 per cent of FAO projects specify strategies to reach women farmers (Staudt 1990:5).

From the point of view of the distribution of responsibility, labour, and power between women and men as workers in public administration, it is possible to map out gender divisions in the administrative structures of most states along horizontal and vertical lines, both across public institutions at a collective level and within them. Women bureaucrats are to be found most often in institutions on the margins of the state apparatus: in the service sectors such as nursing, community care, nursery and primary education, involved in activities often modelled on extensions of women's domestic work. This gender segmentation occurs in public institutions devoted exclusively to these concerns, or in isolated policy desks within 'mainstream' agencies - as is the case with 'home economics' units in agricultural development agencies. Illustrative of this gendered functional division is again the case of agricultural extension services in Africa, where women are mostly absent from the ranks of extension agents trained in crop production: in the mid-1980s on average less than three per cent of African extension agents were women, with a maximum of nine per cent in Nigeria, and most of these were trained in home economics (Berger 1984; Hirschmann and Vaughan 1984).

Even in these sex-typed specializations, women rarely break through management hierarchies to reach policymaking positions. Where governance, economic management, and coercion is concerned in more central state institutions such as the legislature, the iudiciary, revenue collecting services, the police, and the military, women virtually disappear as policy makers, managers, and administrators.

In the past, feminist explanations for the 'misbehaviour' (Buvinic 1986) of gender policy, for the marginalization of women's interests within public institutions generally, and for women's difficulties in climbing managerial hierarchies, have tended to suggest that women's disprivilege is largely the outcome of the operation of basic institutions through which social and economic values are distributed: the market, the household, and private property. ${ }^{2}$ But from the above

to be traced to extra-organizational constraints on women's educational levels and labour-force distribution (e.g. Pollert 1981; Wallace 1982). 
brief inventory, it is evident that the ideological and material factors which contribute to women's poverty and to the devaluation of their productive and reproductive contributions may actually be reproduced by the way women are made objects of policy attention, the way their interests are (or are not) institutionalized, and the way they are distributed as workers within public administration.

Feminist analyses of the gender-differential impact of public administration in development have exposed the fallacies of pretensions to gender neutrality in state policy by demonstrating that citizenship and public policy clientship are gendered. But the persistent misrouting of corrective gender policy measures, and the institutionalization of women's interests on the peripheries of planning, powerfully suggests that administration is also gendered.

\section{WHAT A GENDERED THEORY OF ORGANIZATION WOULD HAVE TO ADDRESS}

What has to be explained is the persistence of male domination across a range of relationships, both internal and external, sustained by public service agencies in development. But for much of conventional organization theory, male domination in organizational structures and outcomes is such a commonplace as to simply not excite theoretical attention or even empirical exploration. Even critical perspectives on organizations which focus on features of control, power, and exploitation within organizations have remained oblivious to the role of gender in shaping organizational power relations (e.g. Bacharach and Lawler 1980; Schaffer 1984; Wood 1985). Certainly this is the case in the enormous body of literature which applies public administration theory to the project of enhancing the responsiveness of rural development bureaucracies to local needs. ${ }^{3}$

A striking example of this is David Leonard's 1977 study of the determinants of the responsiveness of agricultural extension workers to farmers in Western Kenya. Though his use of organization theory produces a set of systematic empirically based propositions on supervision, staff motivation, feedback, and managerial structures to explain the determinants of extension worker behaviour and the consequent class and ethnic biases of the extension service, he entirely overlooks its glaring gender bias - namely, the neglect of women's farming needs in the agrarian economy. Clearly, the 'farmer' whose productivity is at the 'very centre' of Leonard's and the agricultural service's concern (Leonard 1977:2), is not a woman. In contrast, Staudt's study of the same service, in the same period in the same region, demonstrates how stark this oversight is: fully 40 per cent of the farms in the area were female-managed (Staudt 1978a:442).
What produces this gender-blindness in administration? Perhaps because the absence of women as workers in a range of public administrations is so striking, it is tempting to speculate that there is a relationship between the gender of bureaucratic agents and the targets of their interventions. On the other hand, are women's experiences of organizations, both as workers and clients, part of a substantive set of gendered power relations which saturate organization and administration and shape the relationship of administration to society? If the latter is true, then merely adding women on as independent variables affecting the bureaucratic form and bureaucratic outcomes is not enough to explain how and why bureaucracies discriminate against women.

The shortcomings of the failure to recognize gender as a dimension motivating bureaucratic forms and actions (interconnected with other dimensions such as race and class), are evident in one of the first systematic feminist explorations of organizational behaviour, Rosabeth Moss Kanter's study of Men and Women of the Corporation (1977). Moss Kanter suggests that observed sex differences in managerial styles, and women's promotional problems reflect less on women's gender than on their minority status as a group and their underrepresentation on organizational authority hierarchies. In other words, what appear to be sex differences are problems of powerlessness: 'power wipes out sex' (1977:201), and by extension, the gender characteristics of men and women are irrelevant to their prospects within organizations (1977:291-2). But this cannot account for gender differences in experiences of minorities in organizations: male nurses, for example, seem to manage to avoid much of the negative evaluation and lack of job mobility which women face in male-dominated organizations. In contrast, women fail to reach executive and policy-making positions in organizations in which they actually are dominant, as is the case in health, social welfare, and primary education institutions, as well as in much of the voluntary sector.

It also cannot explain why such women as do succeed in climbing organizational hierarchies seem to find it useful to adopt sociological attributes of masculinity in their dress and deportment, in their management styles, or their family responsibilities; minimizing the demands on their time of domestic responsibilities (Hale and Kelly 1989:146-7). In other words, biological and social masculinity seems to confer a certain amount of organizational power.

This is an insight which equal opportunities policies, animated by the suggestion that women's organizational powerlessness is a function of their underrepresentation,

\footnotetext{
3 See Montgomery 1988 for a review of two decades of research on
} rural development administration in developing countries. 
have failed to take on board. As a consequence, equal opportunities policies have yet to fundamentally alter gendered opportunity structures within organizations; they have helped individual women, but not women as a group (ibid:7-13; Lovenduski 1989). They have also yet to make appreciable inroads on upper-level management and on features of organizational structures and cultures which women may find oppressive and obstructive; features such as the organization of the working day around a time schedule which does not accommodate childcare demands, or performance reviews which punish women for taking time out for childbearing. Simply 'adding women on', whether as individuals to organizations, or as categories to conventional organizational theory, fails to either challenge male dominance or specify the connections between masculinity and organizational power. In this conception, bureaucracies are not culpable, and the politics of gender privilege are assumed to occur somewhere else.

What is needed, then, is an appreciation of the connections between gendered social relationships, and gendered organizational relationships in public administration. The gendered 'institutional materiality' (Poulantzas 1973) of organizations must be understood, as must a history of this process, if feminist policy ambitious are to be realized through public administration.

In recent years, feminist students of organizations have argued for a re-theorization of the field of organizational analysis from a gender perspective across a range of expressions of the bureaucratic form: from bureaucratic procedures and discourses (Ferguson 1984; Mueller 1985), to bureaucratic hierarchies and management structures (Acker 1990; Zellman 1976), to the effect of the sex composition of the workforce on workplace cultures (Izraeli 1983; Yancey-Martin 1985). The recognition that sexual harassment may be a component of organizational structure and not the expression of individual deviance (MacKinnon 1979; Gutek 1985), has provoked a concern to theorize sexuality, not just gender, as a key feature of organizational power (Hearn and Parkin 1983; Hearn et al 1989). Since rather little of these feminist approaches has made its way to the empirical study of development administration in the gender and development literature, ${ }^{4}$ I will apply insights from this feminist literature to such information as is available on gender in development administration.

\footnotetext{
${ }^{4}$ An important and consistent exception has been the work of the WID policy analysts Kathleen Staudt and Jane Jaquette, who were among the first to direct attention to the relationship of gendered authority structures in states and public service agencies - or what Staudt has identified as 'gendered bureaucratic resistance' to patterns of gender inequality in society. See Staudt 1978a and b; 1985; 1990; and Staudt and Jaquette, 1988.
}

\section{ADMINISTRATION AND THE GENDERING OF THE PUBLIC AND THE PRIVATE}

Understanding gender as constitutive of, not contingent to, administration involves tracing the connection between gender, power, and organization. The essence of this connection is suggested by Joan Scott's proposal that the definition of gender 'rests on an integral connection between two propositions; gender is a constitutive element of social relationships based on perceived differences between the sexes, and gender is a primary way of signifying relationships of power' (1986:1067).

That gender is constitutive of social relations is familiar enough in the 'domestic' sphere, where gender signals culturally specified divisions of labour, reward, and power in the family or kinship structures. But it is less evident in the case of supposedly gender-neutral 'public' organizations. ${ }^{5}$ Indeed, implicit in the idealtypical Weberian bureaucracy which is based on a separation of a public world of rationality and efficiency from a private world of emotional and personal life, is the notion that neither gender, nor any other 'structures of domination which (have) no rational character' (Gerth and Mills 1958:244) have any place in the merit-based impersonal organizations which replaced rule by patronage. But it is Scott's insistence on a connection between gender and power which invites consideration of the role of gender in the constitution of bureaucratic administration. This is because bureaucracy, as a form of institution and as an organizing practice, is one of the most conspicuous features of the way power and authority are organized and expressed in modern states (Foucault 1981).

Recent socialist-feminist analyses of social policy and public administration in the West have demonstrated that part of the definition of the state and the delimitation of its proper sphere involves the active codification and policing of the boundaries between the 'private' and the 'public' (Fraser 1989). In most modern states, these boundaries also delineate gendered spheres of activity; where the paradigmatic subject of the public and economic arena is male, while that of the private and domestic arena is female. By confirming the institutional arrangements which distinguish the private from the public, public administrations are involved in the social and political institutionalizing of the power asymmetries attached to gender difference, through policy infrastructures which confirm and reinforce women's contractual inferiority in the family and the market.

\footnotetext{
5 In the 'public/private' dichotomy I am discussing here, I take the 'private' to refer to the realm of the 'domestic' - the family, and not to the socio-economic arena of 'civil society'. As Susan Moller Okin points out, there is considerable ambiguity in current usages of the 'public/private' distinction, with the 'private' often taken to include two major societal zones: the (formal) market and a range of other social institutions, and the family (1991:68).
} 
This process, through which connections are forged between men's private and public power, occurs at several levels. To begin with, the modern state structures so celebrated by Weber were built out of a contract which, in its Lockean renunciation of political patriarchy and its relegation of the family to the periphery of the political organization of 'free and equal men' quite literally and explicitly excluded women (Held 1990:103; Pateman 1988; Okin 1991). This was justified by the assumption that unitary gender interests existed both within the family and in relation to the public sphere, such that men as a collectivity were thought to be qualified to represent women's interests, just as individual male heads of households presumed to do this (Hale and Kelly 1989:4-5). This has had enduring implications for the role of public institutions in constructing cultural distinctions between a masculinized public sphere and a feminized private sphere.

In the second place, men's literal, physical monopoly of public organizational space meant that organizational structures, hierarchies, norms, rules, and functional categorizations are designed to accommodate men's, but not women's, socially-constructed labour and time capabilities - namely, their relative freedom from childcare and domestic responsibilities, and the fact that they cannot give birth. As Pateman notes, 'apparently universal categories, such as the individual, the worker, the social or the political, are sexually particular, constructed on the basis of male attributes, capacities, and modes of activity' (1986:7). This bureaucratic grammar of internal rules and procedures directly affects the experiences of women as individual bureaucrats, where the obligation to adapt to organizational forms and practices designed for the bodily presence of men imposes a Procrustean template over their very different bodily functions and family responsibilities. Unable to guarantee the same quantity of time and emotional and physical energies to the organization as men can, women are penalized by exclusion from promotional opportunities, if not by exclusion from the working world altogether.

This literal male dominance has shaped organizational structures and workplace cultures, such that organizational hierarchies, languages, rationalities, means of coordination, and interpersonal interactions are ascribed a gendered character. Whether these distinctive features of administration, such as the valorization of instrumental rationality, top-down command and communication systems, specialization, as well as aggressive, goal-oriented styles of management, represent innate sex characteristics, is a matter of some debate and will be considered below. Again, this has implications for the experiences of women as individual bureaucrats, and as a group, who may favour different styles of management and interaction, but who may find the expression of these preferences penalized.

In the third place, men's monopoly over public forms of material and power resources gives them control over the means of symbolic production (Mackie 1987:28) with the consequence that greater cultural significance has come to be attached to public - and hence implicitly male - activities, while domestic and implicitly female - activities have been inferiorized. This is reflected in organizational value systems, in symbols of success and failure, in the gendering of particular types of skills, of permitted behaviours, and of locations in physical space. In all of this, symbols of masculinity are associated with achievement and accomplishment, and femininity with the opposite. Here too, the symbolic significance of the gendered public/private divide may also be employed to devalue the contribution of women individually and as a group by associating their presence and affectivity with their roles in the private sphere - a feminizing, domesticating, and sexualizing of their public identities. To quote Pateman again, women 'have not been incorporated into the patriarchal structure of capitalist employment as 'workers'; they have been incorporated as women; and how can it be otherwise when women are not, and cannot be, men? The sexual contract is an integral part of civil society and of the employment contract; sexual domination structures the workplace as well as the conjugal home' (1988:142).

The most blatant expression of this is the problem of sexual harassment, now recognized to be more prevalent than ever supposed across a range of institutions, from the shop floor (Pollert 1981), to white collar work (Gutek 1985; Di Tomasso 1989), to the ivory tower (Ramazanoglu 1987). Inescapably, sexual harassment, along with the associations made between symbolic expressions of masculinity and power, suggest that sexuality, as much as gender, is constitutive of organizational relationships. The Weberian supposition that administration can be separated from social relations is exposed as false once women trespass on organizational spaces.

This schematization of the connections between gendering processes, organizations, and power calls attention to the historically produced nature of masculine dominance in organizations. Third World public administrations, with different histories and traditions of socialization (albeit of ten deeply influenced in structure and practice by both Western colonial administrations, and in the context of aid dependency, by donor agencies), can be expected to have institutionalized different expressions of male power, and to be differently involved in the creation and 
policing of boundaries between public and private provision and affectivity, depending upon domestic gender politics. This will have implications for the problems and prospects of feminist policy ambitions in developing countries. Attention to the historically and culturally specific nature of gendered dominance politics within organizations provides a reminder that the structures, cultures and the power associated with gendered agency, and the way this is institutionalized in administrative relationships, is a socially constructed but not a necessary part of administration and is therefore open to change through purposive gender politics.

The role of public administration in gendering processes is of particular importance in developing countries, where it has played a much more central role in the direction and running of the economy than in most Western states. The imperatives of modernization and (sometimes) distributional justice highlight and justify the interventionist responsibilities of the state in the economic and social activities, both public and private, of its citizens. For this reason the political functions of the state are less straightforwardly detached from its administrative apparatuses, and the boundaries between 'public' and 'private' can be differently drawn. National development administrations are politically central in these contexts for another reason - they are the central arenas for competition over resources where conditions of scarcity and generalized poverty have disrupted traditional structures of provision. This makes them one of the most important locations from which gender-linked interpretations of people's needs and appropriate social roles emanate.

In what follows, gendered organizational relationships, structures, and cultures are explored and illustrated with examples drawn mainly from rural development administration in Bangladesh.

\section{GENDERED ORGANIZATION RELATIONSHIPS, STRUCTURES, AND CULTURES}

All organizations evolve characteristic structures adapted to the demands of the labour process, and develop workplace cultures which have their own conventions, formal and informal rules, norms of cooperation and conflict, and channels for exerting influence. For several related reasons, some historical, some inherent to the organization of development work, and some specific to particular cultural contexts, development administrations, both international and national, can be expected to have sharply gendered organizational structures, and strongly masculinized workplace cultures.

Historically, many bilateral aid agencies had their origins in the colonial services that administered the outposts of empire, as is the case with some European bilaterals, or in military supply services transformed after World War II to deliver Marshall Aid to Europe, as is the case with USAID and CIDA. These institutional legacies of imperalist or militarist projects were structured around sharp gender divisions of labour, signalled by such practices as the marriage bar (which was not lifted until 1972) restricting married women's employment overseas in the British foreign services (Ashworth 1985). A particularly masculine institutional culture was symbolized by the ways these organizations valorized myths of adventurous and violent frontier masculinities (provided with a sustaining foil by the virtuous memsahib at home). Malingering symbolic legacies of this gendered process can be found in the militaristic jargon in development planning languages (Leys 1969), and in the belligerently chauvinistic masculine cultures of agency outposts (Tendler 1975; Staudt 1985). ${ }^{6}$

Within certain national contexts, development administrations may acquire powerfully masculinized organizational structures and cultures for cultural reasons. Isolated institutional ethnographies by women rural development agents in North India suggest a highly masculinized workplace culture (Mehendale 1991; Hale 1987). In Bangladesh's purdah culture, rural development is seen as a man's job. Field work requires high mobility, close involvement with large numbers of strangers, and time and energy commitments which stretch far beyond the nine-to-five of an office job; activities, all of which are features of male prerogative in Bangladesh, and female forfeiture. Further, strong cultural prohibitions on women mixing with non-kin men saturate workplace cultures, making them more explicitly masculine than in contexts lacking such intense taboos.

This gendered nature of rural development administration is not just a reflection of culture, nor does the process of minimalizing women's contribution happen automatically. In my study of five NGOs and three state rural development administrations in Bangladesh, I found that organizational structures reinforce these gender divisions by restricting women staff to work on women's programmes which offer few opportunities for management roles, and by channelling them into gender-typed training - a process of gendered

\footnotetext{
${ }^{6}$ Interestingly, the foreign development administrations of nonimperialist countries tend not to demonstrate these sorts of characteristics, and have been the most open to gender policy, to the expanded employment of women bureaucrats, and to the
}

establishment of cross-organizational performance incentives for positive gender policy implementation. These agencies include CIDA and the bilaterals of the Scandinavian Countries. On CIDA see Staudt 1991:23; and on SIDA see Himmelstrand 1990. 
ghettoization and stigmatization (Goetz 1991:268). These stigmatizing choices about the placement and development of women staff were frequently justified by senior male administrators on the grounds that women's family-related mobility constraints made them ineligible for promotions which required relocation, that women lacked the necessary qualifications for training in 'male' specializations, and that in any case, cultural taboos prohibited them from working with a male clientele or moving freely in the countryside.

The cumulative effect of these structural features of rural development organizations is to slow women's advance within organizations, curb their potential influence, and signal that they are not full organizational members. But these effects are not reflections of something immutable in women's social position; rather, they are the consequence of treating organizational rigidities as immutable. Thus, it is true that women's reproductive responsibilities condition their physical mobility and energy in the public realm to a greater extent than men. This is especially so for childbearing and childcare. But these constraints on women's time are unlikely ever to be resolved if they are treated as constraints on the organization, rather than as challenges to be adjusted to by organizational structures. As regards women's qualifications, it is also true in Bangladesh that women enter the working world less well trained than men because of institutionalized obstacles to women's education. But if the organizations in my sample were taking these constraints as given, the women were not; the majority of single women were studying privately to improve their qualifications.

Finally, as regards the claim that cultural taboos on male and female interaction was the greatest obstacle to women's capacity to move out of gender-stigmatized organizational functions, it is true that gender relations in Bangladesh appear to be amongst the least negotiable in the world (Cain et al 1979). But like anywhere else, these taboos are not fixed in stone. Proof of this is that an outpost of one of the NGOs studied, the RangpurDinajpur Rural Service (RDRS) had experimented successfully with assigning women Group Organizers to men's agricultural groups. As one of these women explained, once her displays of competence in agricultural knowledge gained her the respect of the men's groups, the men voluntarily changed their customary meeting time from the evenings, when travel alone for this woman was dangerous, to the day (Bokul Rani Mondol interview, cited in Goetz 1991:233, 237). Other NGOs had been able to overcome constraints on women's public mobility by arranging for them to move in groups for support and protection. These gender-specific modifications to the organizational structures supporting the labour process in rural development are likely to have a stronger gender-transformative effect than will the simple addition of women development agents.

Some feminists argue that certain salient defining features of bureaucratic structures ${ }^{-}$- such as hierarchical calibrations of authority, exclusivist patterns of management and decision-making, functional divisions of labour, and the specification of rules and procedures to guide behaviour and exchange, are themselves expressions of male domination and construct an organizational environment which is particularly hostile to the participation of women and to the receptivity of bureaucracies to the needs of their female clients (Ferguson 1984). Do the flatter organizational hierarchies and more open, participative management and decision-making structures of some collectivist grassroots organizations or some NGOs provide for more gender-egalitarian participation?

The record on this is mixed, not least in the cases of feminist organizational experiments which have found that collective and consensual management does not eradicate problems of domination, let alone coordination (Yancey-Martin 1990; Leidner 1991; Gould 1979). Studies of collectivist organizations which promote participatory democracy, non-hierarchical decision-making, and minimization of status differences have found no necessary correspondence between alternative organizational forms and feminist attitudes and outcomes (Yancey-Martin 1987:547).

Sally Yudelman's study of the Inter-American Foundation found its relatively flat, decentralized operation actually contributed to the invisibility of gender policy issues, despite its participatory, nonhierarchical style and its large complement of female staff (1991). The tendency amongst certain social movements to romanticize alternative organizational forms obscures the limits to how far staff can sustain the amount of energy, experimentation, and uncertainty required by these organizational forms. RothschildWhitt and Whitt's study of collectivist organizations describes serious worker resentment of the extra time required for internal decision-making (1986).

At the very grassroots level, participatory group-based organizational approaches for women of the same class are particularly favoured by some feminist gender policy advocates as a formula for democratic decisionmaking and the building of solidarity networks to support mutual ventures. Yet it can be precisely this very local, molecular structure of association, especially where it includes women of the same kin group, which can harbour some of the greatest tyrannies that women experience. Some women may crave a form of organizational contract free of the small print which deeds over their unpaid labour to sustain ascriptive 
loyalites, even between women, such as the relationship of the daughter-in-law to her mother-in-law.

On the other hand, there is evidence that open command and communications styles can admit of more sensitivity to women's interests. In some international NGOs, such as the Ford Foundation, an equity-oriented value system and participatory and decentralized management structures seem to have encouraged the inclusion of gender policy in development as a major agency goal, with 6 per cent of agency funds directed to women's programmes in the mid-1980s (Kardam 1989:143). But as Nuket Kardam suggests, this shift in agency priorities did not occur until women staff became the majority ( 53.2 per cent) of agency employees. This suggests that egalitarian management structures on their own were insufficient to prompt change.

In my comparison of the Rangpur-Dinajpur Rural Service with the state's Rural Poor Programme in Bangladesh, differences in managerial and administrative style which allowed for a greater bottom-up flow of information and lower-level involvement in decision-making in the NGO accounted for a range of differences between the organizations in motivation, commitment, and productivity (Goetz 1991:207-254). The NGO was also more successful in its group-based development activities with women. However, differences in the receptivity of male and female field workers to the needs of their female clients, as suggested by their attitudes towards, and routines of interaction with their female clients, were found to cut across both organizations. Women field workers in both programmes more readily identified women's subsistence activities as legitimate work requiring productivity-enhancing interventions rather than welfare subsidies. They were more interested than their male colleagues in finding ways of implementing stated programme goals of empowering women, to the extent, in one case, of initiating legal rights training and supporting legal claims against husbands who violated family law.

Women field workers in the state agency also occasionally used their discretion to subvert agency policy in the interests of their female clients. There were a few striking cases of women field officers turning a blind eye to loan investments in sari smuggling from India, adulteration of edible oil, or grain hoarding, all of which were officially forbidden, but much more lucrative than officially sanctioned lowprofit and sex-stereotyped activities such as livestock rearing or paddy husking (Goetz 1991:207-302 passim). If neither the rigid operational procedures of the state programme prohibited its women staff from responding to their clients' needs, nor the more open internal communications structure of the RDRS automatically fostered greater receptivity amongst its male staff to women's needs, then it cannot be assumed that local-level receptivity to women's needs can necessarily be engineered through administrative and managerial reforms.

These findings caution against assuming that organizational structures can be bearers of gendered power independently of the principles and agents which animate them. They also point to the need to understand the role of the gender of bureaucrats, as well as their class, ideologies, and professional ambitions.

\section{THE GENDER OF BUREAUCRATS}

Does the gender of bureaucrats make a difference to the way organizational relations are managed, internally and externally? This question has inspired considerable debate on a number of levels.

Since the Jacksonian experiments in bureaucratic populism, a recurrent theme in American organization theory is the notion that iureaucratic receptivity to client needs is likely to be enhanced where bureaucrats and clients share similar backgrounds and sociological characteristics. This is the basis of representative bureaucracy, which seeks to mirror relative percentages of certain sociological groups in the ranks of public servants, on the assumption that these representatives will act as trustees for the interests of their particular group. Studies of experiments with representative bureaucracy, however, suggest that only weak correlations exist between background and attitude (Denhardt 1984), and that incentives to defend the interests of a particular social group pale in comparison to incentives to conform to organizational systems of motivation and reward (Downs 1967:233).

Do women bureaucrats represent women's interests? Prominent women policy makers across different national contexts have been found to consistently articulate gender-specific policy concerns on such issues as child care, equal pay, maternity benefits, and so on. (Mueller 1982; Hale and Kelly 1989; Dahlerup 1988; Hirschmann 1991). Differences also exist between male and female policy makers on broader policy issues such as the environment, violence in foreign affairs, poverty, and domestic affairs. Jahan's study of women parliamentarians in Bangladesh found women, unlike men, consistently placed poverty over national security as a policy priority (1982).

On the other hand, there is no reason to suppose that women hired to work in development administrations will necessarily be feminists. On the contrary, studies of women in high-level positions have found them to be highly ambivalent about being identified as feminists 
(Mueller 1982; Hale and Kelly 1989; Dahlerup 1988). For many of these women, success is both a function and expression of their ability to conform to organizational structures and cultures by taking on sociological characteristics of men in their dress, deportment, managerial styles, and most importantly, in their capacity to minimize the demands of the home. In a study of women state administrators across California, Texas, Utah, and Arizonia, women were shown to be three times as likely as their male colleagues to be single, divorced, and childless (Hale and Kelly 1989:144). As a minority in most organizations, women have the least interest in challenging dominant agency practices because of the precariousness of individual career positions, and their effective 'minority' status outside of organizations reinforces their need to conform within them (Dahlerup 1988).

Of course, women are to be found at different levels in bureaucracies, and perhaps those found in greater numbers at field/operational levels may be in a stronger position to represent their clients' needs than the few token women at the top of hierarchies. The evidence offered in the last section of differences between male and female field workers' attitudes and behaviour towards their clients suggests this. But it cannot be assumed that these differences are an expression of some natural solidarity or sisterhood between women field workers and their beneficiaries. Whatever the class backgrounds of women field workers, their primary reference group is likely to be their superiors or colleagues, not their clients. To expand on women field workers' constructive use of their discretion, creative strategies are needed to build links between the interests of field workers and clients, and to build cultures of mutual support for women in rural administrations. I will return to this in the next section.

Also militating against women's capacity to express and enact oppositional perspectives on administration is the operation of workplace cultures which trivialize women's organizational presence, as studies in the West (Cockburn 1991; Ramazanoglu 1987), and in the South (Hale 1987; Holloway and Mukurasi 1991; Goetz 1991) have shown. In the rural development administrations I studied in Bangladesh, the increased employment of women had triggered reactions from individual male colleagues and superiors which ranged, with increasing violence, from deference control, negative stereotypes and sexual innuendo, insults and slights on competence, to exclusion from formal and informal networks, undermining of legitimate authority through non-cooperation, and sexual harassment (Goetz 1991:276). These reactions carry gendered statements about worth, space, status and ability, and erect powerful obstacles to women's capacity for personal advance. They construct women's identities as subserviant and primarily sexual - a 'sex-role spillover' (Gutek 1985:40) which brings roles encouraged in private into public work relationships, undercutting women's autonomy from the domestic sphere by defining their identities on the same terms as at home - namely, as structured around providing services for men.

One corollary of the argument, mentioned in the last section, that organizational structures and management cultures inherently express men's interests, is that an alternative, and distinctively 'feminine', approach to organization and management might exist. Kathy Ferguson's radical feminist case against bureaucracy posits the existence of a 'feminine' ethic of care, nurturing, and responsibility to support her case for an alternative organizational form to bureaucracy (Ferguson 1984). Sociological studies of gender differences in management styles do find women to be more open and participative, more comfortable with team work, more responsive to learning from mistakes, and less authoritarian than men (Rosener 1990). But to assume that these differences are innate, as Ferguson implies, rather than active and strategic responses to the unequal organizational distribution of power, is to simply reinforce the discursive stability of notions of difference that devalue women's work in the public sphere. 'Nurturing' styles of management once again bring private gender attributes into the public sphere. Since 'feminine' styles of management may be a response to a lack of power in organizations, it may be counterproductive to advocate them as an expression of female empowerment within organizations, unless ways are found to invest them with social and political power.

Whether greater numbers of women within organizations will prompt gender-sensitive changes in organizations' internal structures and external effects remains an empirical question - there are simply not enough cases of gender-balanced organizations to permit comparison. Here it has simply been suggested that there is no simple correlation between women staff and gender-sensitive administration. Too many other variables, such as organizational structure and culture, intervene to inhibit women's capacity to express oppositional interests. This will have implications for policies to increase women's organizational presence and enhance their performance.

\section{CONCLUSION, AND SOME POLICY IMPLICATIONS}

To recapitulate, I have argued so far that public administration in development has been a poor instrument for implementing gender policies. This is not just because it reflects gender relations in society, 
but because, as a part of social relations, public administration is itself a gendering process. It has played an active, discretionary role in the construction and maintenance of men and women's unequal access to social and economic resources. This perspective may help illuminate the processes and relationships through which other inequalities, such as those of class, race, and the North-South divide, are reproduced in public administration. This argument also raises questions about the very nature of administration and organization, first by dispelling pretensions of genderneutrality, but more importantly, because the focus on gender moves analysis beyond questions of structure and process to questions of power relationships both within administration and between it and society.

On this logic, new forms of public administration in the productive and social sectors will have to take rather different forms than currently envisaged, if a commitment to gender equity is to be a genuine part of corrective efforts to reverse institutional failure in development. The focus on gendered power relationships shows that tinkering with structures, procedures, or representative bureaucracy is inadequate to challenge power systems. These systems, of course, are embedded and endorsed in the broader context in which public administrations are embedded - the state. This means that gender-transformative bureaucratic change cannot occur independently of a political context supportive of women's empowerment; a context with effective women's interest groups and a responsive state. Of course, this conclusion removes practical organizational changes to an inaccessible level, and in any case raises issues which cannot be explored here. There are, however, some immediate implications for public administration which arise from a gendered understanding of organization.

Effective forms of public administration which both respond to women's needs in development and which recognize connections between internal gender politics and external organizational outcomes, will have to find ways of actively disorganizing gendering processes within the organization and between it and society. This can be done by ensuring genuine equity in service delivery, such that the needs of women clients are not sex-stereotyped and stigmatized. Internally, this might be done by introducing women's behavioural and value preferences into the hierarchies, work rhythms, symbolic systems, and organizational facilities which currently reflect men's preferences. Childcare could be brought into the institution, as could flexible time management adapted to the requirements of extraorganizational life. Motivational structures could be adapted to enhance the discretion of women field workers.
Again, the Rangpur-Dinaiupur Rural Service (RDRS) in Bangladesh provides an example of an interesting experiment in improving the receptivity of its women's staff to local women's needs. In 1988 it introduced a 'Central Women's Co-ordination Committee' based on a series of representative committees drawn from women at different organizational levels. It was designed to channel views up from the field to the centre, and as such included at its bottom rung representatives of women programme beneficiaries (Nellis n.d.). Not only did this structure allow for communication and exchange between women staff and beneficiaries, but it symbolically ruptured the distinction between the organization and its social context, thus contributing to a process of democratization. It also provided women in the organization with the possibility of developing cultures of mutual support; a potential resource for challenging male dominance practices within the organization.

The RDRS example gives reasons for optimism that organizations can change, but it has to be acknowledged that in the current development climate, changes of the sort just mentioned are unlikely. Even minimal measures like equal opportunities policies are resented in contexts of high male unemployment. And policies to ensure gender equity are precisely the ones which suffer where concerns with cost efficiency, and introducing market incentives in public administration dominate. Such policies are not about cost-saving (indeed the opposite, given the costs of replacing women's domestic labour), they are not short-term issues, and successful implementation cannot be tied to market incentives and rewards. On this logic, the shift in development administration in the 1980s towards fiscal coordination, and market-oriented forms of structural adjustment cannot be seen as a genderneutral change. Women have been the first to suffer, and to bear the costs, of conservative pro-market and anti-bureaucratic strategies which have sought to reprivatize the costs of reproduction, both within and outside of bureaucracies.

Unlike the market, where women do not tend to fare well, public administration has the power to distribute resources for reducing gender discrimination in access to productive resources, to promulgate laws and policies in women's interests, to offer protection from gender violence at home and in the community, and to alter public discourses about women's inferiority through information systems and education. All the more reason, then, to persist in efforts to transform public administration to reflect women's interests in development. 


\section{REFERENCES}

Acker, J., 1990, 'Hierarchies, jobs, bodies: a theory of gendered organizations', Gender and Society, Vol 2 No 4: $139-158$

Ashworth, G., 1985, 'A glimpse of the international', in G. Ashworth and L. Bonneriea (eds), The Invisible Decade: UK Women and the UN Decade 1976-1985, Gower, Aldershot

Bacharach, S. and Lawler, E., 1980, Power and Politics in Organizations: The Social Psychology of Conflict, Coalitions, and Bargaining, Jossey-Bass, San Francisco

Berger, M., et al., 1984, Bridging the Gender Gap in Agricultural Extension, International Centre for Research on Women, Washington

Buvinic, M., 1986, 'Projects for women in the third world: explaining their misbehaviour', World Development, Vol 14 No 5: 653-664

Cain, M., Khanam, S. R. and Nahar, S., 1979, 'Class, patriarchy and women's work in Bangladesh', Population and Development Review, Vol 7 No 3

Cockburn, C., 1991, In the Way of Women: Men's Resistance to Sex Equality in Organizations, Macmillan, London

Dahlerup, D., 1988, 'From a small to a large minority: women in Scandinavian politics', Scandinavian Political Studies, Vol 11 No 4

Di Tomasso, N., 1989, 'Sexuality in the workplace: discrimination and harassment', in Hearn et al (eds): 71-90

Denhardt, R. B., 1984, Theories of Public Organization, Brooks, Monterey

Downs, A., 1967, Inside Bureaucracy, Little, Brown, Boston

Downs, R. E., 1991, The Political Economy of African Famine, Gordon and Breach, London

Feldman, S. and McCarthy, F., 1984, Rural Women and Development in Bangladesh, NORAD, Oslo

Ferguson, K., 1984, The Feminist Case Against Bureaucracy, Temple University Press, Philadelphia

Foucault, M., 1981, 'Questions of method', Ideology and Consciousness, Vol 8: 4-14

Fraser, N., 1989, Unruly Practices: Power, Discourse and Gender in Contemporary Social Theory, Polity Press, Cambridge

Gerth, H. and Mills, C. W. (eds), 1958, From Max Weber: Essays in Sociology, Galaxy, New York

Goetz, A-M., 1991, 'The institutional politics of gender in rural development policy for women in Bangladesh', unpublished $\mathrm{PhD}$ thesis, Cambridge
Gould, M., 1979, 'When women create an organization', in D. Dunkerley and G. Salaman (eds), International Yearbook of Organization Studies, Routledge and Kegan Paul, London

Gutek, B., 1985, Sex and the Workplace: Impact of Sexual Behaviour and Harassment on Women, Men, and Organizations, Jossey-Bass, San Francisco

Hale, M. and Kelly, M. K. (eds), 1989, Gender, Bureaucracy, and Democracy: Careers and Equal Opportunity in the Public Sector, Greenwood Press, New York

Hale, S., 1987, 'The documentary construction of female mismanagement', Canadian Review of Sociology and Anthropology, Vol 24 No 4: 489-513

Hearn, J. and Parkin, W., 1987, "“Sex" at "Work"', Wheatsheaf, Brighton

-Sheppard, D., Tancred-Sheriff, P. and Burrell, G. (eds), 1989, The Sexuality of Organization, Sage, London

Held, V., 1990, 'Birth and death', in Cass Sunstien (ed), Feminism and Political Theory, University of Chicago Press, London

Himmelstrand, K., 1990, 'Can an aid bureaucracy empower women?', in Staudt (ed): 101-113

Hirschmann, D., 1991, 'Women and political participation in Africa: broadening the scope of research', World Development, Vol 19 No 12: 1679-1694

-and Vaughan, M., 1984, Women Farmers of Malawi, University of California Press, Berkeley

Hollway, W. and Mukarasi, L., 1991, 'Women managers in the Tanzanian civil service', in Adler and Izraeli (eds), Women in Management Worldwide, second edition

Izraeli, D., 1983, 'Sex esfects or structural effects? An empirical test of Kanter's theory of proportions', Social Forces, Vol 61: 153-65

Jahan, R., 1982, 'Purdah and participation: women in the politics of Bangladesh', in H. Papnek and G. Minault (eds), Separate Worlds, Studies of Purdah in South Asia, South Asia Books, Missouri

Kardam, N., 1989, 'Women and development agencies', in R. Gallin and A. Ferguson (eds), Women and International Development Annual, Westview Press, Boulder: 133-154

Leidner, R., 1991, 'Stretching the boundaries of liberal feminism: democratic innovation in a feminist organization', Signs, Vol 16 No 2: 263-289

Lele, U., 1991, 'Women, structural adjustment and transformation' in Christing Gladwin (ed), Structural Adjustment and African Women Farmers, University of Florida Press, Gainsville

Leonard, D., 1977, Reaching the Peasant Farmer: Organization Theory and Practice in Kenya, University of Chicago Press, London 
Leys, C., 1969, 'The analysis of planning', in Leys, C. (ed), Politics and Change in Developing Countries, Cambridge University Press, Cambridge •

Lovenduski, J., 1989, 'Implementing equal opportunities in the 1990s: an overview', Public Administration, Vol 67: 7-18

Mackie, M., 1987, Constructing Women and Men: Gender Socialization, Holt, Rinehart and Winston, Toronto

MacKinnon, C., 1979, Sexual Harassment of Working Women, Yale University Press, New Haven

Mehendale, L., 1991, 'The integrated rural development programme for women in developing countries: what more can be done?' in H. Afshar (ed), Women, Development, and Survival, Longman, London

Montgomery, J., 1988, Bureaucrats and People: Grassroots Participation and Third World Development, Johns Hopkins University Press, Baltimore

Moser, C., 1989, 'Gender planning in the Third World: meeting practical and strategic gender needs', World Development, Vol 17 No 11: 1799-1826

Moss, K. R., 1977, Men and Women of the Corporation, Basic Books, New York

Mueller, A., 1985, 'The bureaucratization of feminist knowledge: the case of women in development', Resources for Feminist Research, Vol 15 No 1: 36-38

Mueller, C., 1982, 'Feminism and the new woman in public office', Women and Politics, Vol 2 No 3: 7-21

Nellis, S., n.d., Policy Re: Women in the RDRS, RDRS, Rangpur, Bangladesh

Okin, S. M., 1991, 'Gender, the public and the private', in D. Held (ed), Political Theory Today, Polity Press, Cambridge

Pateman, C., 1986, 'Introduction: the theoretical subversiveness of feminism', in C. Pateman and E. Gross (eds), Feminist Challenges, Allen and Unwin, London

-1988, The Sexual Contract, Polity Press, Cambridge

Pollert, A., 1981, Girls, Wives, Factory Lives, Macmillan, London

Poulantzas, N., 1973, State, Power and Society, New Left Books, London

Ramazanoglu, C., 1987, 'Sex and violence in academic life, or, you can keep a good woman down', in S. Hammer and M. Maynard (eds), Women, Violence, and Social Control, Humanities Press, New Jersey

Rosener, J., 1990, 'Ways women lead', Harvard Business Review, Nov/Dec: 119-125

Rothschild-Whitt, J. and Whitt, A., 1986, Work Without Bosses: Conditions and Dilemmas of Organizational Democracy in Grassroots Cooperatives, Cambridge University Press, Cambridge

Safilios-Rothschild, C. and Mahmud, S., 1989, Women's Roles in Agriculture: Present Trends and Potential for Growth, UNDP/UNIFEM, Dhaka

Schaffer, B., 1984, 'Towards responsibility: public policy in concept and practice', in E. J. Clay and B. Schaffer (eds), Room for Maneouvre, Heinemann, London

Scott, J., 1986, 'Gender, a useful category of historical analysis', American Historical Review, Vol 91: 1052-75

Staudt, K., 1978a, 'Agricultural productivity gaps: a case study of male preference in government policy implementation' Development and Change, Vol 9: 439-458

-1978b, 'Administration resources, political patrons, and redressing sex inequities: a case from Western Kenya', fournal of Developing Areas, Vol 12 No 4: 399-414

-1985, Women, Foreign Assistance, and Advocacy Administration, Praeger Special Studies, New York

-(ed), 1990, Women, International Development, and Politics: The Bureaucratic Mire, Temple University Press, Philadelphia

-and Jaquette, J., 1988, 'Bureaucratic resistance to women's programmes: the case of women in development', in E. Boneparth (ed), Women, Power, and Policy, Pergamon, New York

Tancred-Sheriff, P., 1989, 'Gender, sexuality, and the labour process', in Hearn et al (eds): 45-55

Tendler, J., 1975, Inside Foreign Aid, Johns Hopkins University Press, Baltimore

Wallace, P. (ed), 1982, Women in the Workplace, Auburn House, Boston

Wood, G. (ed), 1985, Labelling in Developing Policy, Sage, London

Yancey-Martin, P., 1985, 'Group composition in work organizations: a structural-normative view', in S. Bacharach, and S. Mitchell (eds), Research on the Sociology of Organizations 5, JAI Press, Connecticut

-1987, 'A commentary on the feminist case against bureaucracy by Kathy Ferguson', Women's Studies International Forum, Vol 10 No 5: 543-548

-1990, 'Rethinking feminist organizations', Gender and Society, Vol 4 No 2: 182-206

Yudelman, S., 1990, 'The Inter-American foundation and gender issues: a feminist view', in Staudt (ed): 129-144

Zellman, G. L., 1976, 'The role of structural forces limiting women's institutional participation', fournal of Social Issues, Vol 32 No 3: 33-46 